\title{
“Aquela pequena vírgula é meu filho!” A experiência da gravidez na Adolescência.
}

\begin{abstract}
Dina Peixoto De Carvalho'
1 Departamento de Letras, Artes e Comunicação da Universidade de Trás-os-Montes e Alto Douro, Portugal I dina.peixoto@gmail.com I http://orcid.org/0000-0002-2785-8299

Resumo: O estudo aqui apresentado percorreu um caminho diferente daqueles que têm sido seguidos para o estudo da gravidez na adolescência. Procurámos, sobretudo, dar voz às protagonistas da gravidez adolescente, as jovens que engravidam precocemente. Foram propostas, assim, trajetórias de pesquisa que passaram pela adequação de metodologias consagradas de investigação sociológica a um contexto e a um tipo particular de sujeito. Procurámos estudar as experiências das mães/pais adolescentes, a partir das suas histórias, do seu vocabulário, das categorias e termos com que descrevem a realidade das suas vidas. Procuramos explorar temas que exigem a atenção à voz dos atores e a escuta desta. $\mathrm{O}$ estudo reflete e incide sobre as experiências da gravidez na adolescência. $O$ facto de a gravidez precoce constituir um desafio ao desenvolvimento das jovens que pode abrir percursos de vida não imaginados para estas, e o facto de a gravidez na adolescência ser um fenómeno com grande expressão em Portugal estão na origem da definição do objeto desta investigação. Interessou-nos analisar as vivências das jovens/futuras mães e dos pais dos bebés.
\end{abstract}

Palavras-chave: Adolescência; Gravidez; Maternidade.

"That little comma is my son!" The experience of teenage pregnancy."

\begin{abstract}
The study presented here went a different pathfrom those that have been followed for the studyof teenage pregnancy. Above all, we tried to give voice to theprotagonists of adolescent pregnancy, the youngwomen who become pregnant early. Thus, research trajectories were proposed thatwent through the adequacy of established methodologies of sociological research context and a particular type of subject. We tried to study the experiences of adolescentmothers/fathers, based on their stories, their vocabulary,categories and terms with which they describethe reality of their lives. We seek to explore themes that require attentionto the voice of the actors and the listening of theactors. The study reflects and focuses on theexperiences of teenage pregnancy. The fact that early pregnancy is a challenge tothe development of young women that can openup unimagined life paths for them, and the fact that teenage pregnancy isa phenomenon with great expression in Portugal are at the origin of the definition of the object ofthis investigation We were interested in analyzing the experiences of young women/expectant mothers and fathers of babies.
\end{abstract}

Keywords: Adolescence; Pregnancy; Maternity.

\section{Introdução}

Quando começamos a esboçar as primeiras linhas deste texto, fomos assaltados por intensas recordações da nossa primeira ida ao hospital. Íamos entrevistar meninas que viriam a ser mães brevemente. A primeira menina que entrevistamos - a "Carolina" - tinha 15 anos e deveria tornar-se mãe naquele dia ou no dia a seguir. Ouvimos o primeiro relato de uma vivência e uma primeira história reveladora de incertezas e medos quanto ao futuro daquela menina e do seu bebé, confidências sobre as suas experiências. Afinal era mesmo verdade! Poderia ser uma frase de introdução a este excerto. À memória afloravam os momentos que passara quando viu o resultado do teste, quando o namorado, depois de saber, a abandonara, e, como seria de esperar, quando teve de revelar a sua condição aos pais. Para ela, o futuro aparecia como algo difícil de imaginar. $O$ facto de esta jovem não ter condições económicas para cuidar de uma criança é, naturalmente, um fator adicional de agravamento do seu medo e insegurança.

A narrativa da "Carolina" mostra que é justamente nesta fase da trajetória de vida em que ainda não se é adulto - como aliás refere "Carolina" - mas, também já não se é criança, que se procura um sentido/caminho para a vida através de aprendizagens que, se concretizam por tentativas e erros. 
Aos 13 anos, um primeiro amor acabaria por deixar "Carolina" a procurar lidar com a solidão e a tristeza. Esta jovem parecia não conseguir ultrapassar a memória do seu primeiro grande amor, com o qual criou fantasias, projetos e expectativas, apesar de a relação ter sido efémera. Quando teve relações pela primeira vez, namorava "há dois meses." Esse amor era, sobretudo, imaginário feito de suspiros, de olhares, de esperas e de uma grande timidez. "Carolina" viveu uma dramática história de amor ainda muito nova, entregando-se com grande paixão ao seu namorado. Foi difícil para ela lidar com um problema emocional difícil de superar. Enfrentava o seu primeiro dilema. O segundo dilema encontrara-o quando, frágil e desprotegida, se entregou ao segundo namorado e daí resultou uma gravidez indesejada.

Sobressai que uma gravidez na adolescência implica uma entrada precoce no mundo dos adultos, projetando estas futuras mães para novas descobertas, novas responsabilidades, novos desafios, novos contextos de interacção e de atuação.

Porque é que é tão difícil ser adolescente e estar grávida? Para a grávida adolescente, a ocorrência de uma gravidez precoce constitui um desafio desenvolvimental muito exigente. Estas jovens enfrentam uma dupla crise desenvolvimental: a crise da adolescência e a crise da gravidez. Assim, gravidez e maternidade na adolescência encaminham-nos para uma contextualização peculiar porquanto se enquadram numa fase igualmente ela peculiar do desenvolvimento. Pode dizer-se que é a passagem da infância, período da vida caracterizado pela dependência de várias figuras de autoridade, através do crescer psicológico para adquirir a autonomia e a independência. É processo dinâmico, uma cascata de acontecimentos que culminam com a maturidade biológica, psicológica e social dos indivíduos. Este caminhar envolve uma procura de identidade num corpo diferente a cada dia.

\section{Estudo}

O nosso propósito é o de contribuir para, através da análise da voz dos atores, entendermos como são construídas experiências de vida. Procuramos explorar a voz daquelas e daqueles que estão mergulhados/as no mundo da gravidez na adolescência e tentamos entender as vivências e as diferenças que marcam esta experiência. Desta reflexão faz parte uma hermenêutica profunda do outro.

Comecemos pela redefinição do conceito de gravidez adolescente como uma questão sociológica. Uma vez que assume uma indiscutível centralidade ao longo desta investigação, torna-se imperativo empreendermos uma análise da mesma, sob pena de arquitetarmos um discurso descontextualizado e porventura, equívoco.

A problematização da gravidez na adolescência, no contexto das atuais sociedades, passa essencialmente pelo facto deste acontecimento de vida não ser o resultado de um desejo assumido pelas/os adolescentes. Estas gravidezes não estão apoiadas num projeto de vida estável e, muitas vezes, não são bem aceites representando um problema para as suas protagonistas. A explicação mais comum para este fenómeno, em termos sociológicos, reside no colapso dos mecanismos de controlo social, que prolongam o intervalo entre a puberdade e a maternidade/paternidade e que deveriam assegurar os processos educativos fundamentais à prevenção das consequências da fecundidade antecipada na adolescência.

Mas será que esta explicação dá conta do complexo processo através do qual as adolescentes vêm a confrontar-se com a gravidez? E será adequado o foco na gravidez adolescente sem que seja dada a devida atenção à especificidade da experiência da maternidade decorrente de uma gravidez indesejada? Ou, por outras palavras, será que a gravidez adolescente e a maternidade na adolescência podem ser adequadamente tratadas como se fossem o mesmo problema social? Não estaremos, antes, perante dois momentos de um processo que, sob o ponto de vista da experiência das adolescentes (e dos seus companheiros e familiares), configuram problemas diferentes, com consequências distintas para as suas expectativas e projetos de vida? 
Encontramos um mundo onde, após o choque associado à descoberta da gravidez, as adolescentes assumiam que já não tinham medos, receios, temores e angústias quanto à gravidez; o que as assustava, em particular, era o momento do parto, a maternidade e o futuro do bebé. Apercebemo-nos de que, para as jovens que participaram nesta investigação, o tempo que medeia a dúvida de uma possível gravidez e a sua certeza, terá sido particularmente, difícil de um ponto de vista emocional. Bem como, o tempo que dista entre a descoberta da gravidez e a sua revelação aos pais foi sentido de forma particularmente delicada, sendo acompanhado de emoções negativas. No caso das nossas adolescentes, essa situação não se verificava quando a gravidez fora planeada. É de sublinhar que, passado esse momento, não encontramos nos seus discursos nenhum fatalismo em relação à gravidez. Conforme um estereótipo comum, as jovens poderão parecer tão crianças como os filhos que irão nascer, mas agarram-se aos seus bebés como a um novo projeto de vida.

Gravidezes não planeadas podem passar a ser desejadas. A gravidez aparece, nestes casos, como um fator de realização afetiva e, por vezes, de reconstituição de laços sociais.

No contexto das sociedades ocidentais, a gravidez adolescente, enquanto problema, poderá ter várias respostas, desde a interrupção da gestação até ao prosseguir da gravidez. Esta última situação exige para ser viável enquanto projeto, o apoio do pai da criança e da família da jovem. É esta rede que torna possível a criação e consolidação de laços afetivos e sociais que apoiem a própria adaptação das adolescentes a esta metamorfose nas suas vidas. Não obstante, encontramos a inexistência desses laços, associada às implicações biológicas e psicológicas de uma gravidez precoce, que transformam as adolescentes grávidas num grupo de risco, objeto de teorizações e intervenções específicas.

As implicações, em termos sociais, duma gravidez adolescente que tem como desfecho a maternidade revelam-se, fundamentalmente, através da fragilidade e vulnerabilidade, biológica, psicológica e social, da mãe adolescente face à adaptação ao novo papel/função social; as respostas a essa fragilidade e vulnerabilidade passam pela família, pelo sistema de saúde e por outras instituições de apoio social.

Gravidez e maternidade são dois conceitos que, são frequentemente utilizados de maneira indistinta e considerados como sinónimos, mas que de facto representam realidades e vivências distintas. A gravidez ocorre durante um período bem definido de sensivelmente quarenta semanas. Trata-se de um período caracterizado por uma experiência muito particular, que conduzirá, em princípio, à passagem da jovem à condição de mãe. A maternidade é um projeto a longo prazo que tem como pano de fundo a dinâmica de uma sociedade num certo momento que não pode ser previamente delimitado A gravidez transcende o momento da conceção como a maternidade transcende o momento do parto.

A gravidez aparece como um processo contingente, estas contingências não desaparecem com a maternidade, mas são diferentes. Compreender essas diferenças exige uma abordagem da trajetória da gravidez e do seu desfecho. Estamos, no caso da gravidez, perante um processo de transição. Há geralmente um antecipar da passagem por um rito que marca a saída da adolescência e a entrada numa vida adulta. Van Gennep (1972) frisou que há certos momentos em que se ritualiza uma alteração na identidade social do indivíduo como fazendo parte de modificações que ocorrem na inserção destes em novas categorias da sociedade. São momentos críticos que ele designa de ritos de passagem. Para o nosso argumento, é importante frisar o significado de liminaridade, estudado por Turner (1967), que se constrói sobre as ideias da fase de transição - da fase limiar de Van Gennep. Os estados liminares estão associados a uma travessia. No entanto, chamamos a atenção para o facto de nem sempre a idade cronológica ser a chave para a compreensão deste fenómeno. A fase limiar não é vivida por todas as adolescentes da mesma maneira, por isso, deve entender-se como algo de variável de acordo com a classe social, com o projeto de vida e com a relação que a adolescente mantém com a sua família. O fenómeno deve ser abordado tendo em conta os contextos concretos de investigação em que é observado e interpretado. 
Evidenciou-se que as jovens que participaram no estudo tiveram grande dificuldade em responder à questão: sente que pertence ao mundo dos adultos ou continua a pertencer ao mundo dos adolescentes? O estado ao qual elas não se sentem mais pertencentes é ao de criança. Apenas uma jovem nos referiu que ainda era uma criança. Parece-nos que esta passagem para a condição de mãe pode denotar, para algumas das adolescentes entrevistadas, uma saída da liminaridade - não são mais crianças, mas não se sentem adultas - e um ingresso numa nova condição, que podemos denominar de jovens adultas.

A par do objetivo de dar voz às adolescentes surgiu-nos a preocupação de entender até que ponto os discursos de género contribuem para sustentar os discursos sobre as relações íntimas, a sexualidade e a informação acerca dos métodos de contraceção.

O género enquanto categoria reguladora das práticas sociais atua como elemento condicionante da sexualidade. Partimos do princípio, neste estudo, de que as diferenças encontradas entre a voz das adolescentes e a voz dos seus companheiros/pais dos bebés resultam, em boa parte, da imposição de scripts culturais que orientam comportamentos, pensamentos e sentimentos. Esses scripts não são marcados apenas pelo género, mas também por variáveis como a classe social, a idade ou a etnia.

A vivência da gravidez adolescente é marcada por um duplo dilema, ou seja, as adolescentes têm informação sobre a sexualidade, mas verifica-se que essa informação é, muitas vezes, inconsistente ou inadequada, e, em geral, a família tem, nesse campo, um papel limitado. Mesmo acedendo a informação, as jovens parecem não modificar de modo significativo a maneira como vivem a sexualidade e as relações afetivas.

Daqui decorrem algumas interrogações para a (re) construção da gravidez adolescente como um problema social. Uma lista, não exaustiva, sem dúvida, incluiria as questões seguintes: porque procuram as adolescentes relações sexuais que as tornam vulneráveis a uma gravidez precoce? A gravidez na adolescência ocorre numa situação de exclusão social e perante um padrão de dupla dominação, ligada à desigualdade de classe e à diferença de género? Qual o grau de diversidade nas trajetórias de vida destas jovens? Será que a gravidez só ocorre nas adolescentes das classes menos privilegiadas e com menor escolaridade? Como compreender adolescentes que conhecem e têm acesso aos métodos anticoncecionais, e mesmo assim engravidam? Serão identificáveis diferenças nestas variáveis em diferentes grupos étnicos? A atitude de recorrer ao aborto é mais frequente nas adolescentes de status social e económico mais elevado? Como é vivida a experiência de uma gravidez na adolescência? Quem são estas jovens que precocemente engravidam na adolescência? Qual o seu projeto de vida? Quais os seus contextos familiares?

Algumas destas nossas reflexões enquadram-se nas realidades sociais e culturais das sociedades ocidentais onde a gravidez na adolescência é vista como um problema social.

A rede de apoio e as relações significativas na matriz familiar assumem uma pertinência particular perante um episódio de gravidez na adolescência. Contudo a expectativa de receber demonstrações de amor, segurança e carinho, que levassem a um estreitamento e reforço das relações familiares não foi realizada na maioria das famílias das jovens entrevistadas. Faltaram cuidados e proteção, a muitas das nossas Carolinas, Ritas, Joanas, Mafaldas...

Por detrás de pseudónimos estão histórias de adolescentes reais. Engravidaram sem querer. Desvenda-se a história da adolescência, numa linguagem intercalada de sombras e luz, de silêncio e riso, de medo e esperança, de culpa e perdão. Contam-nos histórias de amor, urgentes e inevitáveis, pungentes, nas quais se lê solidão, isolamento e faltas nem sempre redimidas que, no entanto, podem ser resgatadas pelo poder indiscutível da ternura e dos afetos, mas também pela força de novos (e velhos) laços sociais e pela descoberta de novas sociabilidades.

Ouvimos os primeiros medos... Essa teia de desejos, recusas, pânicos e angústias, fizeram-nos ter uma imensa vontade de continuar a ouvir a voz destas adolescentes, uma vez que é nossa convicção que a compreensão da problemática da gravidez em idade precoce passa inevitavelmente pela escuta atenta das suas histórias. 
Tentamos falar com o maior número de grávidas adolescentes que, nos foi possível, facto que nos arrastou para a escuta atenta de 70 jovens.

\section{Metodologia}

Adoptámos uma abordagem de inspiração pragmática, que valoriza a observação empírica e o diálogo permanente entre as teorias pré-existentes e amplamente difundidas, quer pelos meios de comunicação social, quer pelos vários saberes periciais ligados ao tema, e o diálogo com os depoimentos recolhidos no terreno. Não é possível iniciar qualquer investigação a partir de um olhar inocente, neutro e não contaminado pelas teorias pré-existentes. Estas puderam ser entendidas, como um recurso de sensibilização do investigador no terreno. Nos termos propostos por Anselm Strauss (1990), a teoria utilizada foi a ancorada ou fundada (grounded).

O estudo partiu de uma interrogação crítica sobre os modos como a gravidez/maternidade na adolescência tem sido formulados enquanto problema social. Muitos dos relatos e discursos, mediáticos ou profissionais/periciais, tendem a discutir o problema sem considerar as narrativas de experiências e as perspetivas das jovens que engravidam ou que se tornam mães adolescentes, bem como as dos jovens pais.

Embora tenha sido nossa intenção desde o início, realizar um trabalho comparativo, que permitisse analisar o fenómeno da gravidez entre adolescentes em espaços sociais e geográficos diversificados, tal não nos foi possível devido a: limitações de ordem material e de acesso às jovens grávidas. Factos estes, que não permitiram a inclusão de jovens grávidas provenientes de todas as regiões e classes sociais.

Os critérios definidos para inclusão no grupo de entrevistadas foram os seguintes: adolescentes com idades compreendidas entre os 13 e 19 anos até à altura do parto $e$ com 12 ou mais semanas de gestação. Perfazendo um total de 70 narrativas de vida. Não tendo sido nunca nosso intuito construir uma amostra representativa, no sentido estatístico, da população portuguesa.

Restringimos o estudo a algumas regiões do país e aos Hospitais Públicos. Para tal, recorremos aos dados do Instituto Nacional de Estatística disponíveis à data do estudo, facto que nos permitiu selecionar as regiões do país onde o fenómeno das grávidas adolescentes tinha mais incidência. Assim foram compreendidos 11 Hospitais dentro dos distritos de Vila Real e Braga.

Procurámos analisar jovens vindas de uma diversidade de contextos, que tinham em comum as Consultas Externas dos Serviços de Obstetrícia e Ginecologia da Unidades de Saúde selecionadas.

Dado o objetivo fulcral do estudo, optou-se por organizá-lo em torno de uma abordagem qualitativa, mais adequada a uma abordagem compreensiva e interpretativa das experiências das/os jovens confrontados com uma gravidez e/ou maternidade/paternidade precoces. Procurou-se abordar a complexidade e diversidade do fenómeno da gravidez e maternidade/paternidade adolescentes a partir da experiência dos seus protagonistas, as jovens grávidas e os jovens pais. Sendo que uma análise dos significados múltiplos da experiência da gravidez em adolescentes está para além das relações e pressões sobre o corpo fecundo e os discursos estratificados e/ou idealizados. Denote-se que os contextos de desigualdade têm impacto nas subjetividades e decisões acerca dos relacionamentos e da sexualidade. A decisão de pôr no centro da pesquisa a escuta das vozes e das narrativas das jovens ajudou-nos a compreender as suas experiências, para além dos discursos correntes sobre a sua condição, que ignoram ou subordinam essas experiências a um discurso de ordem baseado na sua rotulagem enquanto problema. Quisemos compreender os contextos e significados em torno da gravidez e maternidade num segmento específico da sociedade portuguesa, e das suas implicações em termos das trajetórias biográficas das jovens grávidas, mas também das suas implicações no plano familiar. 
Ao selecionar as pessoas a entrevistar, tivemos o cuidado de o fazer tendo em conta o objetivo de estudar a relação entre sexualidade, gravidez e maternidade/paternidade na adolescência e, em particular, a forma como essa relação se realiza através de diferentes trajetórias e experiências de vida.

Pretendemos, através do recurso a entrevistas tratadas como narrativas de experiência, criar um espaço para que as adolescentes grávidas pudessem dar conta, nos seus próprios termos, de uma experiência ao mesmo tempo singular e comum a outras na mesma situação. Aqui, não se pretendeu produzir um saber com pretensões à generalização. Procurou-se, antes, identificar e caracterizar as convergências, mas também as singularidades das experiências de um conjunto de jovens. Cada entrevista dá conta de uma história singular, irrepetível, dotada de um sentido que, sendo partilhável, está associado a experiências situadas na confluência de uma trajetória social e de um processo de construção da subjetividade. Mas essas narrativas apresentam também algumas semelhanças ou convergências. Elas mobilizam recursos retóricos partilhados e modelos que, analiticamente, podem ser classificados em vários tipos.

Foucault (1994: 16) aborda a problemática do que designa de artes da existência como técnicas de si, no contexto do que considera ser a tarefa de uma história do pensamento: "Definir as condições nas quais o ser humano problematiza' aquilo que é. Aquilo que faz e o mundo no qual vive." Essas artes da existência correspondem a "[p]ráticas reflectidas e voluntárias através das quais os homens não apenas se fixam em regras de conduta, mas também procuram transformar-se a eles próprios, modificar-se no seu singular e fazer da sua vida uma obra que integra certos valores estéticos e responde a certos critérios de estilo" (Foucault, 1994: 17). O objetivo primordial é o de "[s]aber em que medida o trabalho de pensar a sua própria história pode libertar o pensamento daquilo que ele pensa, silenciosamente, e permite-Ihe pensar de modo diferente." (Foucault, 1994: 15).

Procurámos utilizar as entrevistas como um recurso para mobilizar a libertação do pensamento, ainda, que a arte de viver seja mais do que a arte de pensar. Com efeito, cada pessoa, de forma mais ou menos conseguida, de modo mais ou menos consciente e, dentro das condições e contingências que marcam a sua trajetória pessoal, familiar e social, é artesã da sua própria vida. Assim, a dicotomia do objetivo e do subjetivo dá lugar à consideração das narrativas de experiência como processos de articulação de trajetórias e de experiências que representam os sujeitos da vida social. Na linha do que defende Boaventura de Sousa Santos (1987), procurou-se ter em conta que a experiência da realidade social feita de racionalidades plurais, cuja expressão ocorre através de símbolos e de representações, consequentes da sua associação a práticas sociais contextualizadas.

Os resultados do nosso estudo parecem divergir de outros que referem que, em consequência da gravidez precoce, cerca de metade das mães adolescentes rompe a sua relação sentimental com o companheiro. Apesar de não ser baseado numa amostra estatisticamente representativa, o estudo sugere que essas conclusões poderão ter de ser revistas ou qualificadas, dado que a maioria das mães adolescentes continuava, no momento da entrevista, com os namorados.

Trata-se de histórias complexas, em que algumas trajetórias convergentes ou paralelas são matizadas pela singularidade de cada percurso. A tarefa de dar conta dessas histórias, de as analisar e interpretar, obrigou a um trabalho exaustivo, atravessado pela tensão entre a atenção às características comuns dessas histórias e à especificidade de experiências biográficas singulares.

Cada adolescente grávida revelou-nos uma história característica, alicerçada na sua experiência familiar, nos seus medos, desejos e aspirações, bem como na descoberta da gravidez e na adaptação à nova situação, procurando na maternidade uma valorização de si mesma ou uma nova família e a esperança de reconhecimento social.

As adolescentes entrevistadas, na sua maioria, não recorreram a nenhum método contracetivo (e.g. preservativo ou pílula) ou, quando o fizeram, agiram de uma forma que não garantiu a utilização adequada destes. 
O que torna as narrativas de experiência especialmente interessantes, nesta perspectiva, é a possibilidade que elas nos dão de identificar e compreender os contextos e práticas associadas ao que parece ser uma lacuna entre o conhecimento da contraceção e os comportamentos que apontam para algo que contrasta com o que se costuma designar de sexualidade responsável.

Cada entrevista foi analisada em pormenor, com base num esquema preliminar de categorização construído a partir das respostas às questões e, de uma análise de conteúdo. Este exercício de categorização efetuado sobre as palavras das/os jovens permitiu fazer passar afirmações, que à primeira vista nos pareciam banais, pelo crivo de uma interrogação crítica, o que proporcionou um outro entendimento dos contidos das entrevistas. Pudemos, assim, construir uma outra visão da experiência da gravidez adolescente, mais adequada à sua complexidade.

Elaborámos assim uma análise que incluía os pontos de convergência e de dissonância identificados para cada um dos temas considerados. Optámos por conservar o vocabulário dos atores de modo a maximizar a proximidade entre as categorias dos intervenientes e as categorias analíticas. Nesta análise, interessou-nos a forma como os sujeitos interpretam as suas vivências, o que só poderia ser alcançado a partir de um trabalho minucioso sobre o discurso dos próprios sujeitos. A coerência ou consistência desse discurso é uma construção ex post facto, que se constitui através do próprio ato de narração e/ou da interpretação oferecida pelo investigador.

\section{Conclusão}

Sendo um período de mudanças e descobertas, a gravidez adolescente representa uma experiência única para estas adolescentes. Os meses que se seguem à descoberta da gravidez determinam novas experiências a partir das quais, pouco a pouco, se edificam determinados comportamentos, cheios de angústias e medos, mas a partir dos quais as adolescentes começam a construir a representação da sua própria gravidez. Esta fase é considerada bem definida no tempo, e traz consigo alterações físicas que acarretam, do ponto de vista psicológico, vivências muito particulares, permitindo, de uma forma lenta, mas progressiva, a preparação para ser mãe. Esta preparação possibilita empreender cognitivamente papéis e tarefas maternas permitindo que o projeto de maternidade se continue a construir e a consolidar de forma evolutiva. Esta fase vai permitir a incorporação existencial de um filho na identidade da mãe.

A investigação aqui apresentada não tem como intuito propor uma alternativa às abordagens teóricas existentes. O nosso propósito é, antes, o de contribuir para, através da análise da voz das e dos protagonistas dos processos estudados, entender como são construídas as experiências de vida configuradas pela gravidez e pela maternidade adolescentes.

\section{Referências}

Almeida A. N., (2003), "Família, Conjugalidade e Procriação: valores e papéis", in VALA J., et al., (2003), (org.), Valores Sociais: mudanças e contrastes em Portugal e na Europa, Lisboa, Imprensa de Ciências Sociais, Instituto de Ciências Sociais da Universidade de Lisboa pp.50-93.

Almeida A. N., (coord.), (2004), Fecundidade e contracepção, Imprensa de Ciências Sociais, Instituto de Ciências Sociais da Universidade de Lisboa.

Almeida J., (2003), Adolescência e maternidade, Lisboa, Fundação Calouste Gulbenkian, 2a Edição.

Baszanger I., (1992), La Trame de la négociation - sociologie qualitative e interactionnisme, Logiques Sociales, Paris, L'Harmattan.

Bertaux D., (1996), Récits de vie, Paris, Nathan. 
Boisver T. C., (2006), Pais de adolescentes - da tolerância necessária à necessidade de intervir, Lisboa, Climepsi Editora.

Bolonhe J. C., (1986), História do pudor, Lisboa, Teorema.

Bowlby J., (1991), Formação e rompimento dos laços afectivos, Colecção Psicologia e Pedagogia, Editores Diversos.

Brazelton T., \& Cramer B., (1990), Les premiers liens, Paris, Stock/Laurent Pernout.

Brenot P, (1996), L'éducation sexuelle, Presses Universitaires de France, (Collection «Que saisje?»-Poche).

Burgess R., (1997), A pesquisa no terreno : uma introdução; Oeiras, Celta Editora.

Carvalho, D. 2013, "Aquela pequena vírgula é meu filho" - a experiência da gravidez na adolescência. Húmus.

Daguerre A., \& Nativel C., (2004), Les maternités précoces dans les pays développé: problèmes, dispositifs, enjeux, politiques, CERVL, Institut D'Études Politiques de Bordeaux.

Dewey J., (2006), Logique - La théorie de l'enquête, Paris, PUF, 2a Édition.

EriksoN E., (1972), Identidade, juventude e crise, Rio de Janeiro, Zahar.

Foucault M., (1994), História da sexualidade I - A vontade de saber, Lisboa, Relógio D’água.

Freud, (2010), Três ensaios sobre a teoria da sexualidade, Lisboa, Relógio D’Água.

Giddens A., 1995, Transformações da intimidade - sexualidade, amor e erotismo nas sociedades modernas, Oeiras, Celta Editora.

Glaser B. G., \& Strauss A. L., (1967), The discovery of grounded theory: strategies for qualitative research, Chicago, Aldine.

Guerra I., (2006), Pesquisa qualitativa e Análise de conteúdo - Sentidos e forma de uso, Estoril, Principia Editora.

Santos S. B., (1987), Um discurso sobre as ciências, Porto, Edições Afrontamento, 1a Edição.

Strauss A., (1987), Qualitative analysis for social scientists, Cambridge University Press

Strauss A., \& Corbin J., (1990), Basics of qualitative research. Grounded Theory Procedures and Techniques, Newbury Park, CA, Sage.

Strech P., (2001), Preciso de ti - Perturbações psicossociais em crianças e adolescentes, Lisboa, Assírio \& Alvim.

Turner V., 1967, The forest of symbols: aspects of Ndembu ritual, Ithaca: Cornell University Press.

Kintzinger S., (1996), Mães: um estudo antropológico da maternidade, Lisboa, Editorial Presença 2a Edição. 